\title{
Lugar de Memória e Arte: Rastros de uma escola
}

\author{
Place of Memory and Art: \\ Traces of a school
}

\author{
Francione Oliveira Carvalho ${ }^{1}$ \\ Ana Beatriz Marques Penna ${ }^{2}$ \\ Vitor Fernando de Barros Sant' $\mathrm{Ana}^{3}$
}

\footnotetext{
1 Doutor e Mestre em Educação, Arte e História da Cultura pela Universidade Presbiteriana Mackenize, com Pós-Doutorado em História pela FFLCH/USP. Bacharel em Artes Cênicas pela Unespar/FAP e licenciado em Artes pela Belas Artes de São Paulo. Atua na Faculdade de Educação da Universidade Federal de Juiz de Fora. É líder do MIRADA- Grupo de Estudo e Pesquisa em Visualidades, Interculturalidade e Formação Docente.

E-mail: francioneoliveiracarvalho@gmail.com,

Currículo Lattes: http://lattes.cnpq.br/6262224578426097

${ }^{2}$ Bacharel em Artes e Design e Licenciada em Artes Visuais pela UFJF. Artista e educadora em espaços não formais. Desenvolve projetos de curadoria e expografia. E-mail: ana.penna@design.ufjf.br,

Currículo Lattes: http://lattes.cnpq.br/8163302754739248

2 Bacharel em Artes e Design e Licenciado em Artes Visuais pela UFJF. Arteeducador, pesquisador e artista. No momento é professor de Arte no Ensino Fundamental na cidade de São José dos Campos, SP. E-mail:vitor.barros@design.ufjf.br,

Currículo Lattes: http://lattes.cnpq.br/8132687029616180
} 


\title{
Resumo
}

Este texto parte das provocações de Fischer, Loponte (2020) a respeito dos modos de habitar a escola, e, no convite que fazem para olharmos para a escola pelo que é possível de inventar e criar nela. Dentro deste contexto tece diálogo com autores como Masschelein, Simons; Helguera; Bosi; Vergara; Irwin, para refletir sobre Lugar de Memória e Arte, projeto vinculado ao PIBID da UFJF que propôs uma série de proposições de fruição e criação artística com estudantes do segundo ciclo do Ensino Fundamental de uma escola pública da cidade de Juiz de Fora, Minas Gerais. O projeto também promoveu trocas de experiências entre esses estudantes e artistas convidados, o que possibilitou habitar um museu com obras criadas na escola pelos participantes dos encontros, revelando com isso, uma escola que inventa e que ocupa espaços.

\section{Palavras-chave}

Escola; arte; memória, criação, PIBID.

\begin{abstract}
This paper starts from the provocations of Fischer and Loponte (2020) regarding the ways of inhabiting the school, and from their invitation to look at the school for what is possible to invent and create in it. In this context, it engages in dialogue with authors such as Masschelein, Simons; Helguera; Bosi; Vergara; Irwin, to reflect on the Place of Memory and Art, a project linked to the PIBID project at the Federal University of Juiz de Fora (State of Minas Gerais, Brazil) that suggested a series of propositions of fruition and artistic creation with students from the second cycle of elementary school in a public school in the city of Juiz de Fora, State of Minas Gerais (Brazil). The project promoted exchanges of experiences between these students and invited artists, which made it possible to inhabit a museum with works created at the school by the participants of the meetings, thus revealing a school that invents and occupies spaces.
\end{abstract}

\section{Keywords}

School; art; memory, creation, PIBID.

ISSN: 2447-1267 


\section{Encontros possíveis entre arte e educação}

Lidar com a incerteza e as contradições vivenciadas numa sala de aula exige uma articulação entre teoria e prática que revela uma práxis política inerente ao saber docente. Fischer; Loponte (2020) afirmam que é necessário pensar a escola de outros modos, convidando-nos "a pensar sobre o que se passa na escola como o espaço do instituído e o que o atravessa, impossível de ser previsto e controlado" (p.14). Para Masschelein; Simons (2015) a escola instaura a skolé, tempo para o estudo e para a atenção atenta ao mundo, uma interrupção das expectativas e obrigações relacionadas a "um determinado espaço fora da escola" (p. 36).

É neste espaço fronteiriço e de margem que nosso texto irá povoar. Afinal a fronteira é essencialmente o lugar da alteridade, o lugar do encontro dos que por diferentes razões são diferentes entre si, "a um só tempo, um lugar de descoberta do outro e de desencontro" (Martins, 2009, p. 133). O lugar do encontro que provocou este texto é uma escola pública localizada no interior de Minas Gerais, "os diferentes entre si" que acolheram nosso convite foram alunos do segundo ciclo do Ensino Fundamental, e, o motivador deste encontro foi o PIBID - Programa Institucional de Bolsas de Iniciação à Docência da UFJF, realizado no ano de 2019 (Fig.1).



Fig.1. Registros fotográficos do Projeto Lugar de Memória e Arte, 2019, Juiz de Fora/MG. Foto: Rayana Bianchetti. 
O PIBID foi criado a nível federal no ano de 2007. Fundamenta-se no diálogo entre a universidade e a escola e, na aproximação dos/das licenciandos/as do espaço escolar. Afinal, como aponta Nóvoa (2012), se o ensino e o trabalho escolar são o coração da profissão docente, é na escola que devemos centralizar a formação dos futuros professores. Contudo, nesse artigo não nos debruçaremos na discussão específica sobre o PIBID, ou sobre o PIBID e o ensino de arte, pois já há uma grande produção referenciada que promove estas reflexões (Gonçalves; Machado, 2014; Rocha; Silva, 2015; Bruno, 2015; Costa, 2016; Santos; Sacardo, 2018; Rossi, 2018). Nosso objetivo é pensar a partir das provocações de Fischer; Loponte (2020) a respeito dos modos de habitar a escola, "nos encontros entre arte e educação, convidando a olhar para a escola pelo que é possível inventar e criar" (p. 14).

Acreditamos que a primeira ação na tentativa de habitar a escola é abrirse a ela, compreender a cultura da escola, aqui compreendida como os arranjos e as negociações realizadas pelos membros de uma comunidade escolar, que cria condutas, crenças, valores e práticas que marcam as experiências dos sujeitos que habitam o território compartilhado (Gimeno Sacristan, 1999; Forquin, 1993). A escola que habitamos fica na região central da cidade de Juiz de Fora, os alunos vêm de regiões muito diferentes, sendo a escola, muitas vezes, seu único território em comum. O reconhecimento das particularidades que cada um trazia foi fundamental para começarmos a tecer uma proposta de atuação naquele espaço, com aquelas pessoas.

Além de perceber a diversidade presente na escola, foi necessário compreender como a arte se manifestava naquele território, como ela se materializava no cotidiano escolar, no currículo, nos processos de criação vivenciados pelos estudantes. Constatouse que as questões da arte e da cultura estavam circunscritas ao componente curricular Arte, sendo que ele não era ofertado em todos os anos do segundo ciclo do Ensino Fundamental, apenas nos $7^{\circ}$ e $8^{\circ}$ anos, não havendo nenhum outro espaço na escola destinado para pensar e fruir arte ou vivenciar propostas criativas e expressivas.

As aulas de Arte, acompanhadas durante o PIBID, se organizavam, em geral, pela ideia de desenho livre e livre expressão do aluno, a velha prática do laissez faire (FERRAZ; FUSARI, 2009). Outras vezes, a partir do desenho pronto. Os alunos ganhavam imagens pobres e estereotipadas para colorir. Havia alguns momentos teóricos, nos quais ficava evidente certa pesquisa, entretanto, as informações "dadas" eram pouco significativas ora pela superficialidade do conteúdo apresentado, ora pela valorização exagerada de momentos da história da arte descontextualizados e centrados em si mesmos, sem trânsito para outras propostas e experiências. A ação consistia em copiar da lousa pequenos textos sobre um período ou artista no caderno de Arte. Não havendo reflexão sobre o tema estudado, ampliação do repertório artístico cultural dos estudantes ou promoção de leituras imagéticas sobre os períodos ou artistas tratados. As imagens não adentravam a sala de aula.

Como fazer com que a arte habite de outras formas essa escola? Criar possibilidades de encontro e de experiências significativas? Ressignificar o tempo e o espaço que é vivenciado coletivamente? A partir destas provocações foi criado 
o projeto Lugar de Memória e Arte ${ }^{1}$, um espaço de encontro e experimentação aberto a todos os estudantes da escola, todas às sextas-feiras após as aulas regulares. Aproximadamente vinte alunos retornavam todas as semanas para participar das ações. Uma possibilidade de prestar atenção ao mundo tal como defendem Masschelein; Simons (2015) e Helguera (2018, p. 84), "a arte é um espaço que criamos em que podemos deixar de subscrever as exigências e regras da sociedade; é um espaço em que podemos fingir, brincar, repensar as coisas, pensá-las do avesso".

É curioso como a ausência da arte, como componente curricular obrigatório nessa escola, evidenciou a necessidade de arte na vida. Os estudantes que mais sentiram-se afetados a participar dos encontros semanais foram os alunos que não tinham aulas regulares da disciplina. Essa acolhida indicava a vontade e o desejo de vivenciar novas experiências. Reconhecer os desejos como forças tensionais que nos movem para determinados fins e que quando alcançados proporcionam prazer foi uma possibilidade real de habitar de um jeito novo essa escola. Afinal, a apatia que observávamos nos alunos cotidianamente e, principalmente, no decorrer das aulas de Arte, podia ser reflexo da falta de desejo de todos que ali estavam, tanto de professores quanto de alunos. Dessa forma, "refletir sobre desejos é também articular deslocamentos, possibilidades e ações" (CARVALHO, 2019, p. 974).

Martins e Picosque (2012) ao discorrerem sobre o público de uma exposição afirmam que cada pessoa "traz consigo suas referências pessoais, suas expectativas, seus saberes, seus medos" (p. 16), é com essa bagagem que os mediadores terão que lidar. Da mesma forma ocorre numa primeira aula ou no encontro com uma nova turma. Os professores/propositores também terão que lidar com as bagagens trazidas pelos alunos, e, tal como eles, também trarão suas expectativas para esse encontro. "Toda esta intricada trama configura a mediação como difícil e apaixonante tarefa" (Martins; Picosque, 2012, p. 16).

\section{O Lugar de memória e arte como território da criação}

Os primeiros encontros do projeto Lugar de Memória e Arte foram de reconhecimento, de experimentos e partilha. Conversávamos sobre o cotidiano, produzíamos vestígios, tentávamos compreender o tempo, quem éramos e o espaço onde estávamos. Os encontros também possibilitavam desconstruir os discursos e os imaginários que atrelam à escola a ideia de laboratório para o mundo produtivo do trabalho. Sobre isso, Masschelein; Simons (2015, p. 36), sinalizam que não basta apenas a interrupção temporária do tempo, "mas também a remoção das expectativas, necessidades, papéis e deveres ligados a um determinado espaço fora da escola".

A arte e os processos de criação, por sua vez, ativavam e materializavam o que vinha sendo experienciado. Dessa forma, os encontros foram caminhando para

1 "Lugar de Memória e Arte", proposta criada por Ana Beatriz Marques Penna e Vitor Fernando de Barros Sant'Ana dentro do subprojeto do PIBID da licenciatura de Artes Visuais da UFJF coordenado por Vanessa Raquel Lambert de Souza, que ocorreu entre os meses março e julho de 2019, numa escola da cidade de Juiz de Fora. 
a investigação das memórias, afetividades, apagamentos e formas de registro das experiências individuais e coletivas existentes no ambiente escolar. Estimulando uma aproximação entre os estudantes e os processos artísticos, uma reflexão sobre a importância da memória na construção da identidade e possíveis caminhos de inserção da arte no ambiente escolar.

Mas o que é afinal a memória? Como ela é construída? Qual a diferença entre apagamento e esquecimento? Eram muitas as perguntas para debater com as crianças. Bosi (2003) diz que a memória é um trabalho sobre o tempo vivido, invocado pela cultura e pelo indivíduo. De alguma forma, a crise do tempo da sociedade contemporânea faz com que a arte esteja constantemente evocando esse tema. Pois, enquanto linguagem, ela é instrumento fundamental da memória para subverter a temporalidade, pincelar novas subjetividades e revelar nuances sobre quem somos e estamos sendo.

A memória pode ser compreendida como um conjunto de ideias e impressões que partem da experiência para reafirmar o vivido. Ela é uma construção intelectual e psíquica de um evento do passado, porém, não é estática, pode ser ressignificada a partir de um novo olhar sobre a experiência. Talvez um fato que tenha ficado registrado na nossa memória possa ser reconstruído a partir de novas vivências ou o surgimento de novos fatos. Algo muito comum na História, onde descobertas e vestígios modificam nossa maneira de olhar e compreender o passado. Por estar ancorada na experiência vivida flertará sempre com a realidade, mas o tempo e as novas experiências, muitas vezes, embaralham o real e confundem a lembrança do que ocorreu.

$\mathrm{Na}$ arte contemporânea a memória é um conceito muito explorado pelos artistas. Eventos importantes e traumáticos marcaram a experiência de diversos povos e sociedades ao longo do século XX e XXI, e artistas apropriaram-se da arte para expressar as dores e as experiências comuns das pessoas. Portanto, a memória é um processo individual, mas também pode se dar pela coletividade. A memória coletiva é construída pelas lembranças e acontecimentos vivenciados pelos diferentes grupos. Afinal, "o conjunto das lembranças é também uma construção social do grupo em que a pessoa vive e onde coexistem elementos da escolha e rejeição em relação ao que será lembrado" (BOSI, 2003, p. 54).

A partir deste contexto, os encontros semanais com os estudantes foram divididos em três módulos: memórias individuais; memórias coletivas; e memórias no espaço-tempo. Desde o início nos apropriamos da ideia de palimpsesto, uma superfície em que há rastros de marcas anteriores, as quais são levemente visíveis. Jatahy Pesavento (2004, p. 26) afirma que no palimpsesto há uma superposição de camadas de experiências de vida que incitam ao trabalho de um desfolhamento, "de uma espécie de arqueologia do olhar, para a obtenção daquilo que se encontra oculto, mas que deixou pegadas, talvez imperceptíveis, que é preciso descobrir". Essa compreensão de palimpsesto foi o fio condutor de todos os encontros com duração de uma hora e participação livre. Para materializar esse conceito e estimular a criação de novos vestígios, foi produzido no primeiro encontro, para cada aluno, 
um livro de artista palimpsesto, composto por páginas de livros didáticos antigos de arte, que com uma camada sutil de primer, uma solução utilizada geralmente para preparar e neutralizar superfícies que receberão uma pintura, permitia novas inscrições e possibilidades de pensar os percursos, os registros, e até mesmo o ensino de arte (Fig. 2).

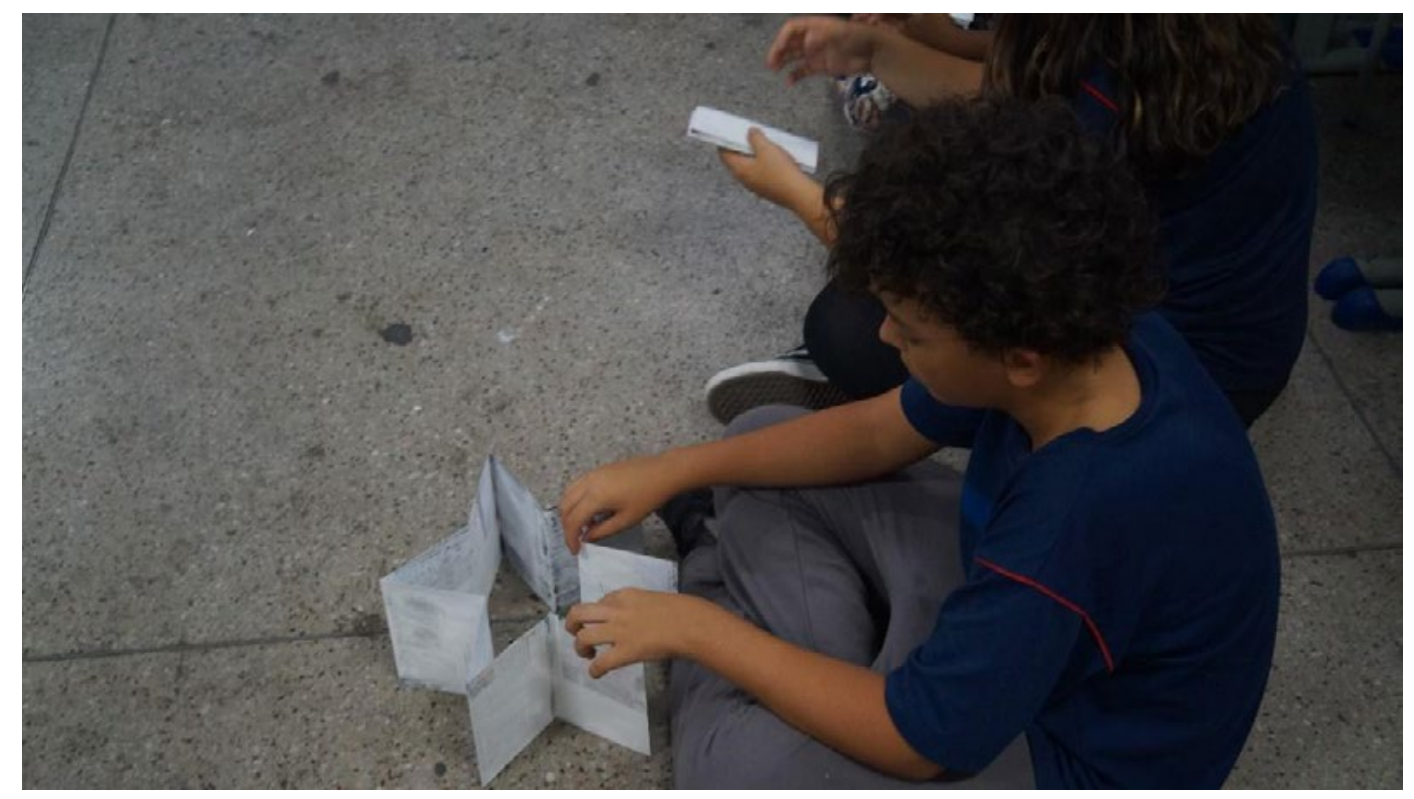

Fig.2. Registros fotográficos do Projeto Lugar de Memória e Arte, 2019, Juiz de Fora/MG. Foto: Rayana Bianchetti

Havia a preocupação em construir, colaborativamente, novas camadas de vivências possíveis dentro do ambiente escolar. Assim, cada objeto produzido vinha de um exercício de atenção a si mesmo, às memórias que nos fazem quem somos, ao cotidiano, ao outro e o que ele traz consigo. Por meio de rodas de conversas, momentos de fruição, criação, contextualização (BARBOSA, 1991), não necessariamente nesta ordem, materializou-se discussões e trabalhos artísticos, ora individuais ou coletivos. Os alunos ouviram histórias, criaram poesias, bordaram, quebraram pratos, assistiram filmes, desenharam, dobraram, registraram.

Fayga Ostrower (1983) afirma que criar significa integrar o compreendido em novo nível de consciência, transformando as informações recebidas em linguagem própria. Assim, a criação depende tanto das convicções internas da pessoa, de suas motivações, quanto de sua capacidade de usar a linguagem no nível mais expressivo que puder alcançar. Este fazer é acompanhado de um sentimento de responsabilidade, pois se trata de um processo de conscientização.

As atividades propostas no decorrer dos encontros visavam alcançar essa dimensão, ajudar os estudantes a compreender as informações recebidas e transformálas em estímulo para uma busca autoral e expressiva. Neste sentido, as proposições criavam condições tanto para a manifestação da subjetividade quanto da diversidade presente no grupo. Se, por um lado, o estímulo à individualidade e subjetividade deve ser valorizado na criação, por outro, é preciso levar em consideração que os 
processos criativos se tecem com a multiplicidade de experiências e conhecimentos que habitam o sujeito, construídos a partir da convivência nos vários espaços sociais. Essa compreensão de criação aproxima-se da ideia de atividade criadora proposta por Vigotski (2018) e problematizada por Stein (2019) ao afirmar que nela as ações dos sujeitos manifestam-se de modo combinatório ou criador quando o resultado é a criação de novas imagens ou ações, e não a simples reprodução de imagens ou ideias anteriores:

Nessa perspectiva, os processos de criação são compreendidos na relação dialética entre reproduzir e criar, pois enquanto a atividade reprodutora, ligada à memória, permite a conservação das experiências vivenciadas pelos sujeitos, a atividade combinatória ou criadora, ligada à imaginação, possibilita a transformação dessas representações, dando origem a algo novo (STEIN, 2019, p. 09).

Dessa forma, a atividade reprodutora pensada a partir da memória, e não da cópia, integra o processo criativo. Quanto mais ricas forem as experiências artísticas e estéticas vivenciadas pelos alunos, possivelmente, maior será o repertório a ser acessado e reelaborado por eles. Na expectativa de nutri-los esteticamente, algumas das proposições realizadas nos encontros foram conduzidas por artistas convidados. "A nutrição estética na sala de aula é um modo de gerar o abastecimento dos sentidos movendo o saber sensível pelo oferecimento aos aprendizes de diferentes objetos culturais" (MARTINS; PICOSQUE, 2012, p. 36).

Foram convidados dois artistas conhecidos pelos propositores do projeto que tinham disponibilidade de tempo para frequentar a escola e, interesse nas fricções entre arte e educação centradas na A/R/Tografia (IRWIN, 2013), metodologia de pesquisa educacional baseada em arte que busca explorar a tríade artista-pesquisadorprofessor. Dessa forma, partindo de suas investigações, Isabella Frapiccini e Lucas Soares propuseram experiências sensíveis que procuraram integrar a emoção, a reflexão e a criação.

Isabella Frapiccini apoiou-se no projeto "Bordado, memória e valorização de mulheres artistas a partir do resgate de técnicas artesanais tradicionalmente femininas", para oferecer uma proposição dividida em dois momentos: no primeiro, um material de mediação construído por caixas de recordação fictícia de quatro artistas: Frida Kahlo, Criola, Claudia Andujar, Tomie Ohtake, que visava explorar tanto a poética de cada uma, quanto os diálogos que estabelecem com a memória individual e coletiva. No segundo momento, os estudantes eram convidados para reinterpretarem essas memórias por meio de uma experimentação com a técnica do bordado (Fig. 03 e 04). As manualidades surgiram em diálogo com o conhecimento contemporâneo em arte, e não associadas ao trabalho manual repetitivo, não autoral, em série, que remetem ao universo da produção e da técnica, destituídas da compreensão de produção artística como processo intelectual (ACASO, 2009). 

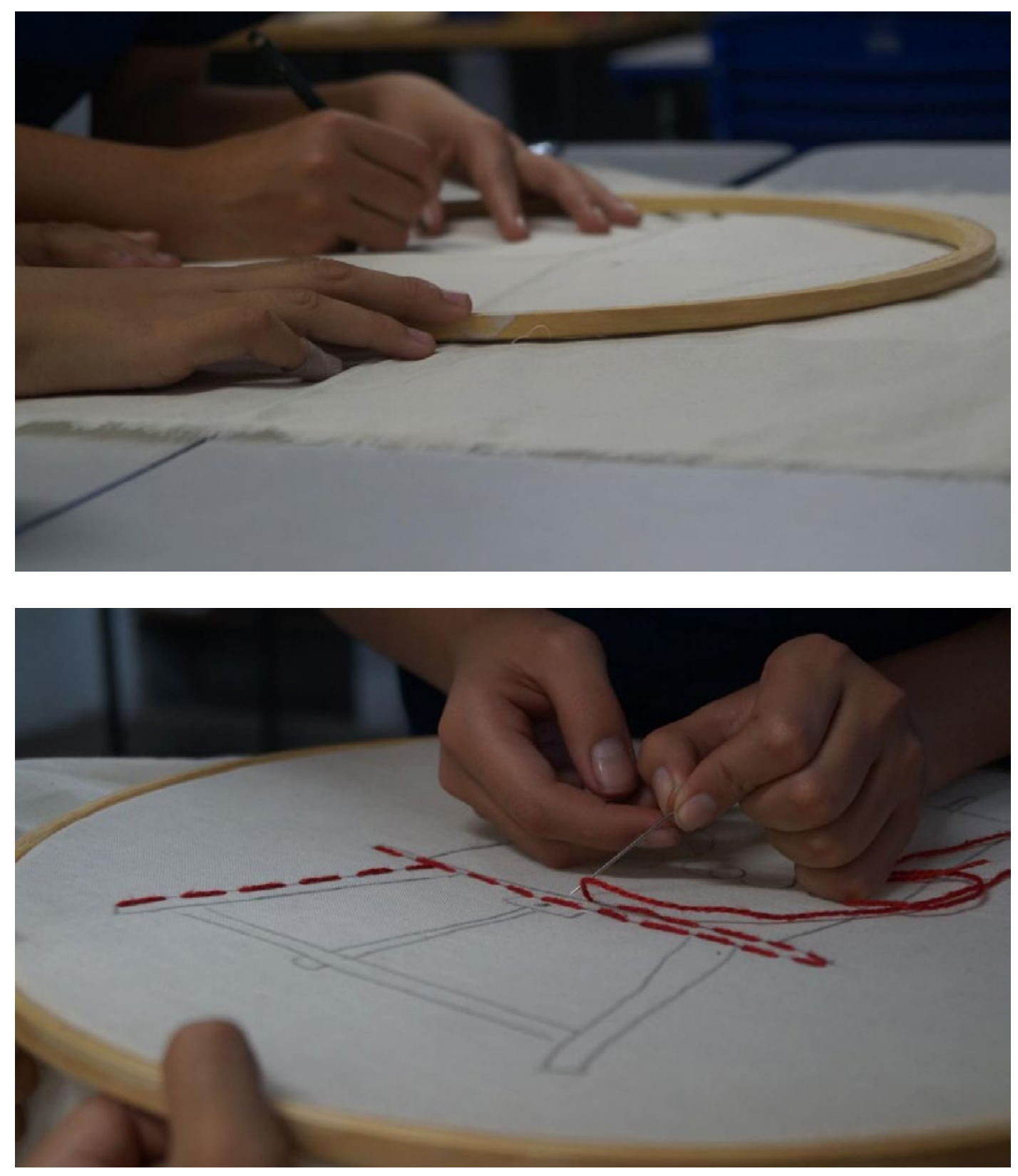

Fig.3 e 4. Registros do processo de criação da obra coletiva Memórias Bordadas, 2019, conduzida pela artista Isabella Frapiccini, Juiz de Fora/MG. Fotos: Bia Penna

O artista Lucas Soares explora em suas obras diferentes materialidades e procedimentos artísticos que têm em comum a ressignificação das memórias presentes nos objetos. A ação do tempo, das pessoas, ou ambas, marcam e afetam os objetos. Se as "coisas têm peso, massa, volume, tamanho, tempo, forma, cor, posição, textura, duração, densidade, cheiro, valor"2 , elas podem ser constantemente transformadas. Soares procurou ativar nos estudantes a imaginação e a poesia que pode desprender dos objetos quando destituídos da sua função original (Fig. 5). Novas materialidades 
e interpretações que dão forma e sentido às ideias e aos sentimentos. Afinal como reitera Blondet (2018, p.73) "contemplar uma obra renunciando à ansiosa e à imediata atribuição de significados é, sem dúvida, um exercício de caráter imaginativo".

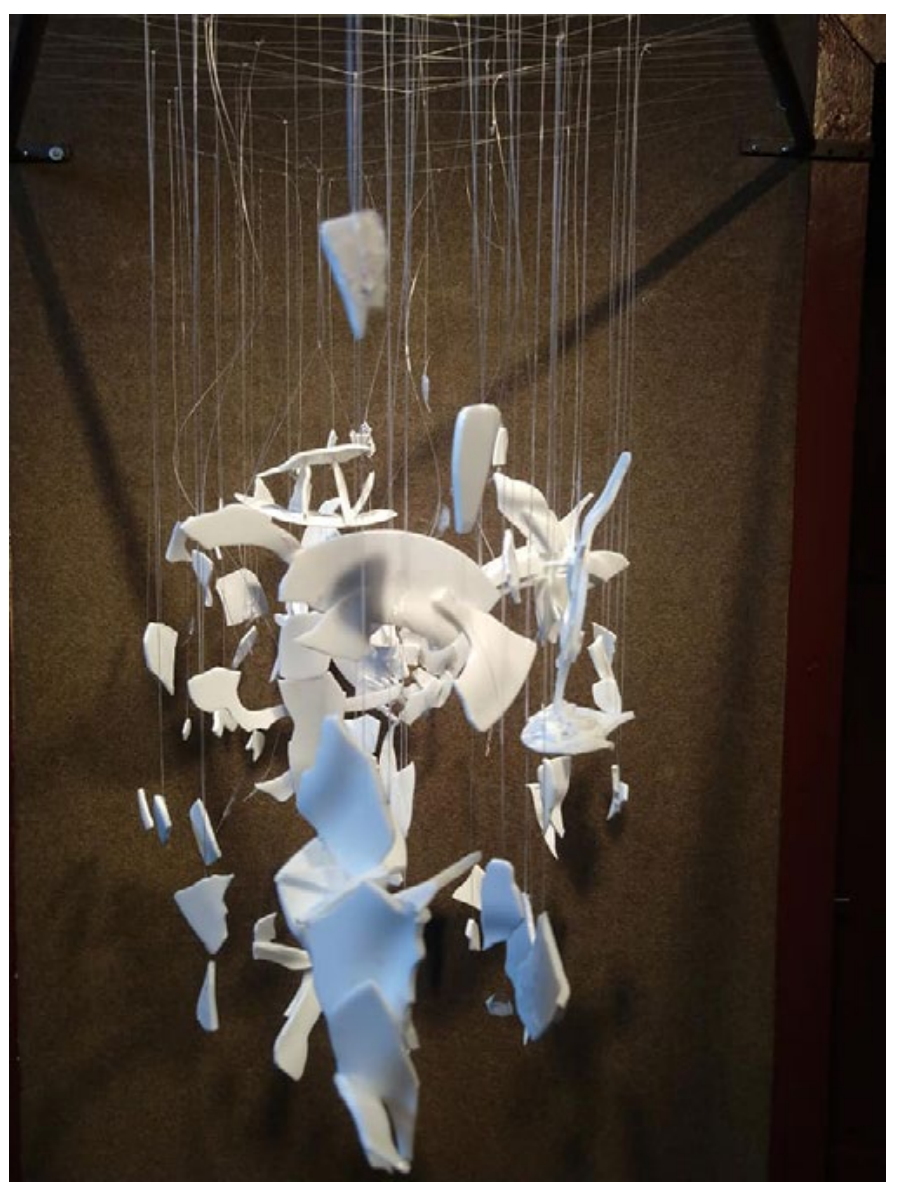

Fig.5. Registro da obra coletiva Da poesia das coisas: reminiscências, 2019, criada a partir da oficina conduzida pelo artista Lucas Soares, Juiz de Fora/MG. Foto: Francione O. Carvalho

\section{A escola que habita o museu}

Durante a realização dos primeiros encontros do projeto surgiu a oportunidade de inscrevê-lo em um edital para uma mostra de 15 dias, no Fórum da Cultura da UFJF, em Juiz de Fora. Considerando a disposição dos participantes em discutir a temática e o engajamento com as proposições criativas, foi construído um projeto de exposição em que as criações e os processos de trabalho seriam socializados com toda a comunidade. Ampliando, com isso, os ecos do trabalho realizado. Com a aprovação do projeto, o Lugar de Memória e Arte virou exposição e foi habitar outro território: o museu.

Ao discutir a relação entre artistas e museus, professores e escola, e refletir sobre a crítica institucional, Helguera (2018) afirma que a melhor maneira de ser revolucionário é aprender a ser institucional. "Em vez de criticar o sistema atual, instaurar um novo que torne supérfluo ou irrelevante o sistema anterior" (HELGUERA, 
2018, p. 89). Ou seja, não basta somente identificar a ausência de arte na escola, a falta de interesse dos alunos em relação às aulas de Arte, a desmotivação dos professores em criar proposições que desafiem os estudantes, a inexistência de oportunidades de ampliação de repertórios e experimentações artísticas e autorais. É necessário reconhecê-las, confrontá-las e encontrar brechas dentro da própria instituição escolar para modificar a maneira dela se relacionar com a arte e a cultura.

[...] Pensar a escola de outros lugares, entendendo-a, em parceria com a arte contemporânea, como espaço de resistência ao que está instituído, através de movimentos micropolíticos, expressos nas ações cotidianas, que constroem a "possibilidade de fazer uma escola outra na escola estabelecida" (Gallo, 2015, p. 442), (FISCHER; LOPONTE, 2020, p. 14).

Mas como criar o Lugar de memória e arte dentro de um museu? Bastaria levar para outro espaço os rastros do que foi vivido coletivamente na escola? Apresentar para outras pessoas o caminho que foi percorrido, e com sorte, gerar reflexões sobre o tema? Habitar um museu com obras criadas com a colaboração de crianças e adultos reafirma a compreensão da escola não apenas como um espaço de difusão de saberes, mas um lugar de troca e criação artística. Uma escola que inventa, que ocupa espaços e se abre para o seu entorno.

A partir da ideia de curadoria educativa (VERGARA, 2018) e a compreensão de que "tornar a arte acessível a um público diversificado é torná-la ativa culturalmente" (p. 42), buscou-se revisitar os trabalhos desenvolvidos durante a oficina, não como meros resultados, mas como disparadores para novas reflexões sobre os temas da memória, da escola e da arte/educação. As obras foram reorganizadas a partir da potência enquanto objeto artístico para ocupar o espaço institucional de uma exposição, na expectativa de descobrir o que acontece quando os trabalhos escolares rompem com os muros da escola.

Se durante os encontros o projeto almejou construir um espaço acessível de criação e discussão de arte na escola, a exposição, em si, foi um convite para que os alunos conhecessem e ocupassem os espaços culturais da cidade. A exposição (Fig. 9 e 10) permitiu que eles mediassem suas produções e fossem percebidos como artistas e propositores, não apenas pelo público, mas também por eles próprios. Além de oportunizar que os mediadores do projeto, licenciandos de Artes Visuais e bolsistas do PIBID, explorassem a A/R/T/grafia (IRWIN, 2013) e as Metodologias Artísticas de Pesquisa em Educação (ROLDÓN; VIADEL, 2012). Afinal, a abordagem artográfica pressupõe o trânsito sem hierarquia entre as dimensões do criar, do pesquisar e do ensinar, entendendo o artista/pesquisador/professor como um ser hibrido e inventivo.

As experiências artográficas resultaram em criações como Inventário, Rituais, e Cartografias de um encontro. Em Inventário (Fig. 6), por via dos sentidos visual e tátil, recuperou-se informações de experiências vivenciadas por cada estudante. Foram acessadas memórias e criado um inventário de objetos e de histórias particulares. Ele pôde ser acessado na exposição a partir de fones de ouvido.

Em Rituais (Fig.7), questões diversas a respeito do cotidiano, tais como: 
percebemos nossas repetições cotidianas? E aquilo que sai da rotina? Como lidamos com a forma que vivemos? Nos damos conta do que fazemos no dia a dia? Nos perguntamos o porquê fazemos o que fazemos? A partir das tentativas de respondêlas, os alunos criaram uma poesia visual, que transformada em lambe-lambe, se repetiu em rolos de papel. Juntas, alargaram as experiências individuais de cada aluno e teceram novos padrões e sentidos.

Quando um espaço se transforma em lugar? Enquanto a palavra "espaço" é, muitas vezes, utilizada no cotidiano de maneira genérica, um "lugar" é uma área que foi apropriada afetivamente. Deste modo, por meio de uma construção coletiva, com os alunos participantes, pretendeu-se mapear os atravessamentos e documentar o lugar criado no espaço/tempo nos encontros promovidos pelo projeto. Assim, na obra Cartografias de um encontro (Fig.8) revisitando seus percursos cotidianos, os estudantes resgataram o caminho feito para chegar à escola. Pelo fato de estar localizada em uma região central, os territórios de pertencimento nem sempre eram comuns a todos. O que ficou evidente nos caminhos traçados com caneta hidrográfica sobre o papel. Assim, indivíduos com histórias distintas, de locais diferentes, tinham o espaço da escola que ocupavam e o desejo de produzir arte de forma voluntária como elos de ligação. Dessa conexão emergiram trocas e afetividades, bases para a consolidação desse ambiente de reconhecimento de subjetividades. Os trajetos de cada aluno foram fotografados, vetorizados, impressos e materializados em cubos. Com rotas e percursos distintos, os cubos, reorganizados, permitem encontros e desencontros que, na tridimensionalidade, mapeiam o que viria a ser este lugar.

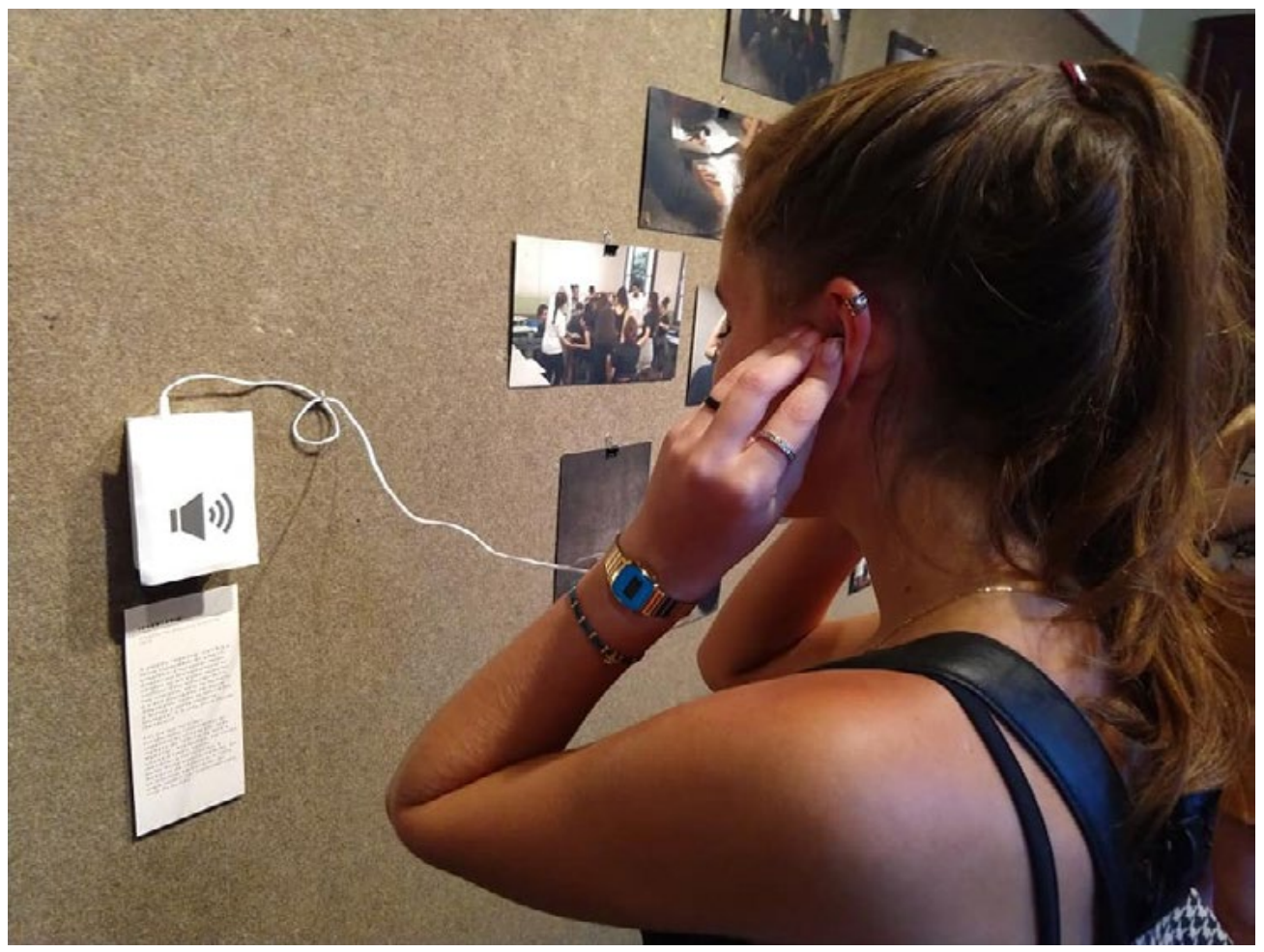

Fig.6. Registro da obra coletiva Inventário, 2019, exposição Lugar de Arte e Memória: Rastros de uma escola normal, Fórum da Cultura, Juiz de Fora/MG. Foto: Francione O. Carvalho 


\section{Revista Apotheke}

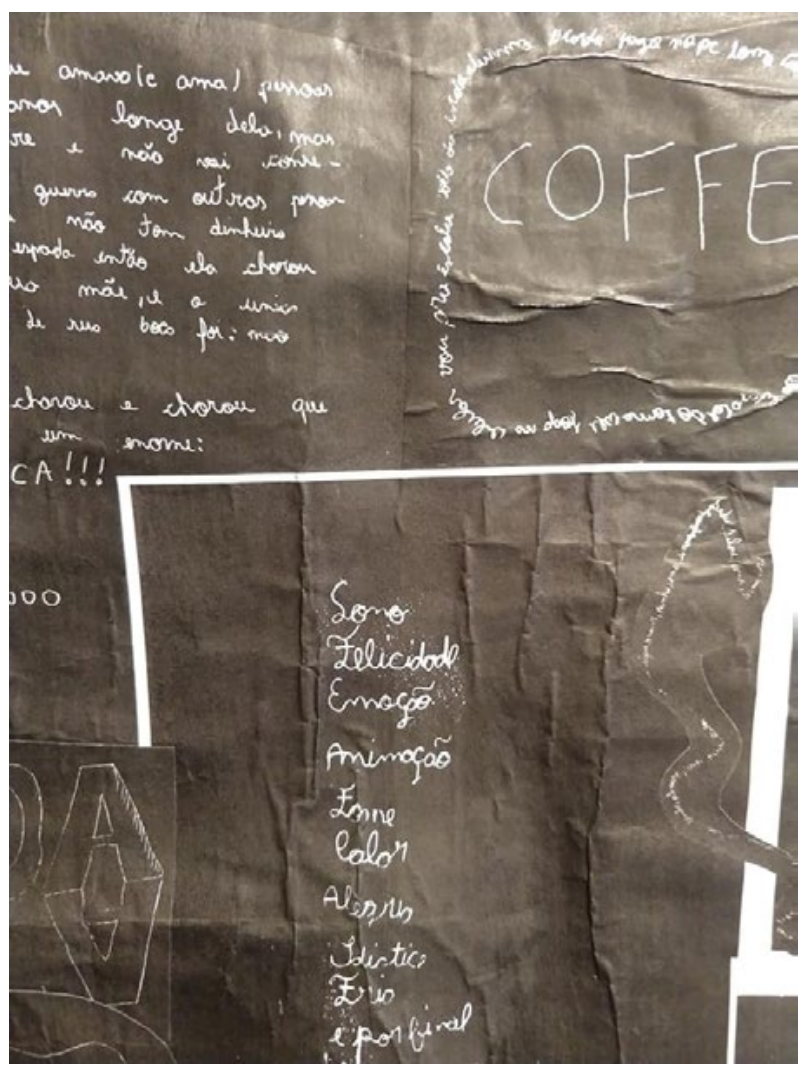

Fig.7. Registro da obra coletiva Rituais, 2019, exposição Lugar de Arte e Memória: Rastros de uma escola normal, Fórum da Cultura, Juiz de Fora/MG. Foto: Francione O. Carvalho

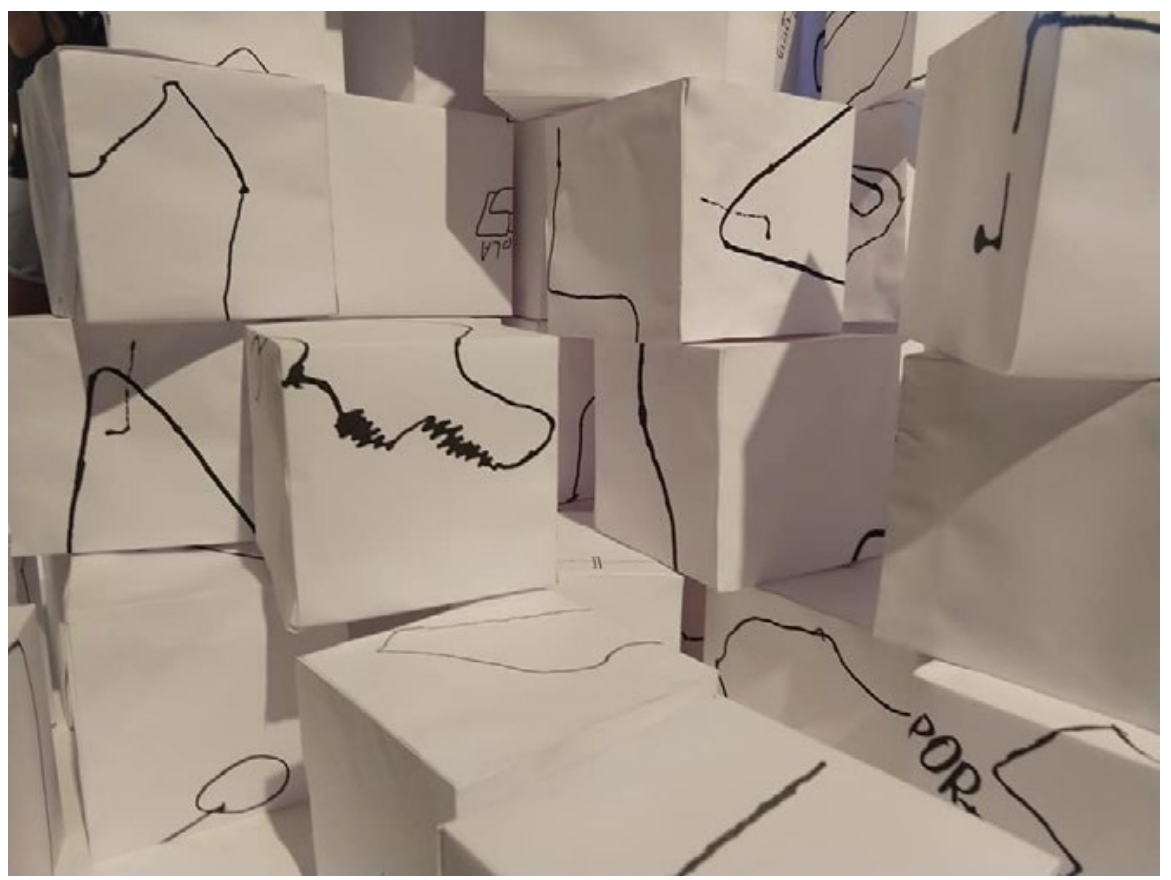

Fig.8. Registro da obra coletiva Cartografias de um encontro, 2019, exposição Lugar de Arte e Memória: Rastros de uma escola normal, Fórum da Cultura, Juiz de Fora/MG. Foto: Francione O. Carvalho 


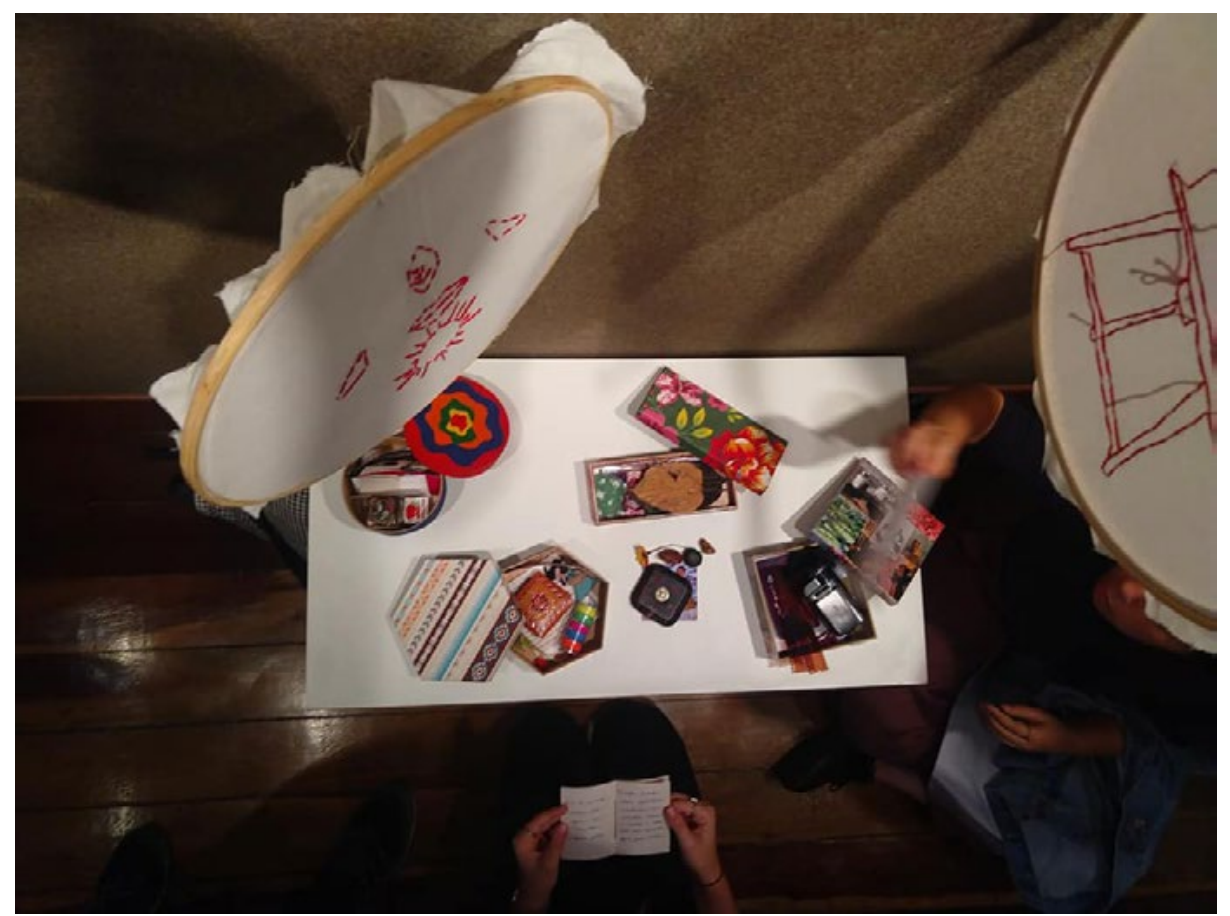

Fig.9. Registro da obra coletiva Cartografias de um encontro, 2019, exposição Lugar de Arte e Memória: Rastros de uma escola normal, Fórum da Cultura, Juiz de Fora/MG. Foto: Francione O. Carvalho

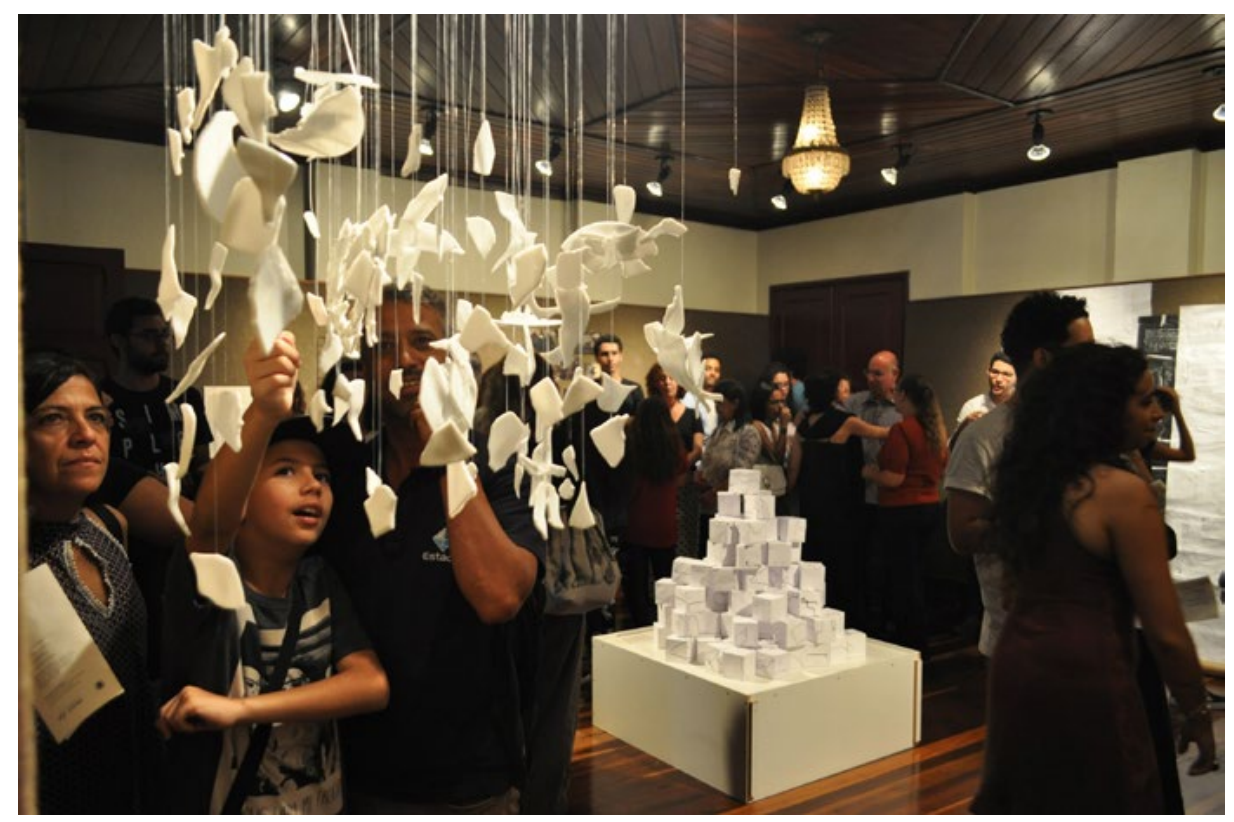

Fig.10. Registro da obra coletiva Cartografias de um encontro, 2019, exposição Lugar de Arte e Memória: Rastros de uma escola normal, Fórum da Cultura, Juiz de Fora/MG. Foto: Divulgação Fórum da Cultura.

\section{Considerações finais}

Se a criação está diretamente relacionada às experiências do indivíduo criador como afirma Vigotski (2018), é necessário que na escola os estudantes tenham o máximo de oportunidades de conhecer e explorar as possibilidades estéticas que a 
arte propicia. Experiências que possam ampliar e promover encontros significativos com a arte e a cultura. Dessa forma, é urgente que docentes, mediadores e professores em formação encontrem brechas no tempo e espaço das instituições para criar novos modos de ocupar e viver a escola. Tornem-se propositores de espaços de diálogo, experimentação e reflexão conjunta.

É necessário estimular os futuros professores a trabalhar com os processos e aprender a produzir conhecimento a partir de seu contexto, de suas condições, de suas questões e limitações. Assim, o ato de aprender não deve ser encarado como conformista a um ambiente dado, uma simples adaptação a uma realidade já existente, mas um processo de criação e intervenção no mundo. Uma aprendizagem inventiva que seja capaz de inventar problemas, de pensar e agir de maneira autônoma e criativa.

$\bigcirc$ ato de questionar e experimentar permeou as proposições do projeto Lugar de Memória e Arte, pois ele reforçou a importância de valorizar situações de aprendizagens abertas à investigação permanente de todos os envolvidos nos processos de educação/criação. Se hoje vivemos numa sociedade do esquecimento marcada pela velocidade, falar de memória é buscar instaurar um outro tempo, onde seja possível vivenciar experiências que possibilitem prestar atenção ao mundo, às pessoas, aos encontros, à escola que ocupamos.

\section{Referências:}

ACASO, María. La educación artística no son manualidades: nuevas práctivas em la ensenanza de las artes y cultura visual. Madrid: Catarata, 2009.

BARBOSA, Ana Mae. A imagem do ensino da arte: anos oitenta e novos tempos. São Paulo: Perspectiva, 1991.

BOSI, Ecléa. O Tempo Vivo da Memória: Ensaios de Psicologia Social. São Paulo: Ateliê Editorial, 2003.

BLONDET, José Luis. Mal-educados. In: In: CERVETTO, Renata; LÓPEZ, Miguel A. Agite antes de usar. Deslocamentos educativos, sociais e artísticos na América Latina. São Paulo: Edições Sesc São Paulo, 2018.

BRUNO, Eliane Bambini Gorgueira. O PIBID do Instituto de Artes da Unesp: Espaço de conexões. Anais [recurso eletrônico] do 240 Encontro da Associação Nacional de Pesquisadores em Artes Plásticas, setembro de 2015, Santa Maria, RS ; Nara Cristina Santos ... [et al.] (orgs.). - Santa Maria : Associação Nacional de Pesquisadores em Artes Plásticas ; Universidade Federal de Santa Maria, PPGART ; Universidade Federal do Rio Grande do Sul, PPGAV, 2015. Disponível em: http://anpap.org.br/anais/2015/. Acesso em 27 jul. 2020.

CARVALHO, Francione Oliveira. Imagens e palavras para pensar a escola: apontamentos sobre a reforma do Ensino Médio. Revista Ibero-Americana de Estudos em Educação, 
Araraquara, v. 14, n. 3, p. 973-985, jul./set., 2019. Disponível em: https://periodicos.fclar. unesp.br/iberoamericana/article/view/10621. Acesso em 27 jul. 2020.

COSTA, Tayanne Cid. Contribuições do PIBID/UNAMA Artes Visuais para alunos do $5^{\circ}$ ano de uma escola municipal de Belém. Anais do XXVI CONFAEB: POLÍTICAS PÚBLICAS E ENSINO DA ARTE: Interculturalidade e processos educativos em Artes Visuais, Dança, Música e Teatro". Boa Vista, novembro de 2016 (CD-ROOM).

HELGUERA, Pablo. Uma má educação. Entrevista por Helen Reed. In: CERVETTO, Renata; LÓPEZ, Miguel A. Agite antes de usar. Deslocamentos educativos, sociais e artísticos na América Latina. São Paulo: Edições Sesc São Paulo, 2018.

FERRAZ, Maria Heloísa C. de T. FUSARI, Maria F. de Rezende. Metodologia do Ensino de Arte: fundamentos e proposições. São Paulo: Cortez, 2009.

FISCHER, Deborah V. LOPONTE, Luciana G. Modos de habitar a escola: o que somos capazes de inventar? Revista Educação (UFSM), Santa Maria, v. 45, jan/dez, 2020. Disponível em: https://periodicos.ufsm.br/reveducacao/article/view/35041/pdf. Acesso em 27 de jul.2020.

FORQUIN, J.-C. Escola e cultura: as bases sociais e epistemológicas do conhecimento escolar. Porto Alegre: Artmed, 1993.

GONÇALVES, Maira Gutierres. MACHADO, Gilberto Andrade. VIDA, ARTE, ESCOLA: CONFLUÊNCIAS NA FORMAÇÃO DOCENTE NO PIBID ARTES VISUAIS - IFCE. Revista Iniciação \& Formação Docente Formação docente: Múltiplos olhares v.1 n.1 (2014) Abril - Outubro / 2014. Disponível: http://seer.uftm.edu.br/revistaeletronica/index.php/ revistagedeles/article/view/862. Acesso em 27 de jul. 2020.

GIMENO SACRISTÁN, J. Poderes instáveis em educação. Porto Alegre: Artmed, 1999.

IRWIN, R. A/r/tografia: uma mestiçagem metonímica. In: DIAS, Belidson. IRWIN, Rita L. (Organizadores). Pesquisa educacional baseada em arte: a/r/tografia. Santa Maria: Ed. Da UFSM, 2013.

JATAHY PESAVENTO, Sandra. Com os olhos no passado: a cidade como palimpseto. Esboços: histórias em contextos globais, Florianópolis, v. 11, n. 11, p. pp. 25-30, jan. 2004. ISSN 2175-7976. Disponível em: <https://periodicos.ufsc.br/index.php/esbocos/article/ view/334>. Acesso em: 27 jul. 2020.

MARTINS, José de Souza. Fronteira: a degradação do Outro nos confins do humano. São Paulo: Contexto, 2009.

MASSCHLEIN, Jan. SIMONS, Maarten. Em defesa da escola: uma questão pública. Belo Horizonte: Autêntica Editora, 2015.

NÓVOA, A. Devolver a formação de professores aos professores. Cadernos de Pesquisa em Educação - PPGE/UFES, Vitória, ES. a 9. v.18, n. 35, p. 11-22, jan./jun. 2012.Disponível: 
http://teste.periodicos.ufes.br/educacao/article/download/4927/3772>. Acesso em: 07 fev. 2020.

OSTROWER, Fayga. Universos da arte. Rio de Janeiro: Campus, 1983.

ROCHA, Stéfani Rafaela Pintos da; SILVA, Maria Cristina da Rosa Fonseca da. PIBID Interdisciplinar: um olhar sobre as contribuições da arte para a construção de objetos pedagógicos para pessoas com deficiências. Revista do Grupo de Pesquisa Educação, Artes e Inclusão. Florianópolis, v.11, n. 1, p. 127-144, outubro, 2015. Disponível em: http:// www.revistas.udesc.br/index.php/arteinclusao/article/view/6398. Acesso em 27 de jul. 2020.

ROLDÁN, J.; VIADEL, R. M. Metodologías Artísticas de Investigación em Educación. Málaga, Espanha: Ediciones Aljibe, 2012.

ROSSI, Maria Helena Wagner. PIBID na formação inicial de professores de Artes Visuais na UCS. Revista Interdisciplinar de Ciência Aplicada. Edição Especial: Vol. 3, n 5, março de 2018. Disponível: http://www.ucs.br/etc/revistas/index.php/ricaucs/article/view/6079/3231. Acesso em 27 de jul. 2020.

SANTOS, Halisson Keliton Ramos dos.; SACARDO Michele Silva. A política de formação de professores: o estado da arte sobre o Pibid na Pós-Graduação em Educação. Revista on line de Política e Gestão Educacional, Araraquara, v. 22, n. 3, p. 1168-1181, set./dez., 2018. Disponível em: https://periodicos.fclar.unesp.br/rpge/article/view/11404. Acesso em 27 de jul. 2020.

STEIN, Vinícius. As crianças são artistas natas? Reflexões sobre a atividade criadora e as artes visuais na educação escolar. In: II Encontro Internacional da Rede Visível. Londrina, PR: Universidade Estadual de Londrina, 2019.

VERGARA, Luiz Guilherme. Curadoria educativa: percepção imaginativa/consciência do olhar. In: CERVETTO, Renata; LÓPEZ, Miguel A. Agite antes de usar. Deslocamentos educativos, sociais e artísticos na América Latina. São Paulo: Edições Sesc São Paulo, 2018.

VIGOTSKI, L. S. Imaginação e criação na infância: ensaio psicológico. Tradução de Zoia Prestes e Elizabeth Tunes. 1. Ed. São Paulo: Expressão Popular, 2018.

Recebido em 13 de julho de 2020.

Aprovado em 30 de julho de 2020. 